\title{
Coexistence of hairy-cell leukemia and histiocytic lymphoma
}

\author{
HARVEY ROTHMAN, D.O. \\ Stratford, New Jersey \\ MONICA SPAULDING, M.D \\ MARIO MONTES, M.D. \\ Buffalo, New York
}

\begin{abstract}
A 69-year old man initially presented with hairy-cell leukemia (HCL), as evidenced by splenomegaly and the presence of abnormal mononuclear cells with irregular cytoplasmic borders in the peripheral smear. A year later, pathologic examination after diagnostic splenectomy and lymph node biopsy showed histiocytic lymphoma. Cell surface marker studies suggested B-cell proliferation. Bone marrow biopsy and electron microscopy were compatible with the presence of hairy cells, but the mononuclear cells were negative for tartrate resistant acid phosphatase staining. Chemotherapeutic treatment of the lymphoma was followed by leukopenia and then death. The occurrence of two B-cell disorders in one patient leads to speculation whether the two entities simply have similar characteristics or are part of a spectrum of a single disorder.
\end{abstract}

Hairy-cell leukemia (HCL) has been described in numerous reports ${ }^{1-3}$ as a slowly progressive disorder characterized by the triad of pancytopenia, splenomegaly, and abnormal circulating, mononuclear cells with irregular cytoplasmic projections. However, the nature of the characteristic cell remains under discussion. Studies of the hairy cell with either electron microscopy, cell-surface markers, histochemical staining, or functional characteristics have still not led to a consensus. ${ }^{4-9}$

In 1979, two cases of HCL in which malignant lymphoma also developed were reported. ${ }^{10,11}$ Lymphoma was present in one patient at the diagnosis of HCL, ${ }^{10}$ whereas it appeared later in the second patient. ${ }^{11}$ Vardiman and coworkers ${ }^{12}$ reported, also in 1979, an autopsy study of five patients with HCL in which, at postmortem examination, one patient had lymph nodes which microscopically contained large bizzare cells similar to those of malignant lymphoma "histiocytic type." There have also been published reports of HCL mimicking lymphoma ${ }^{13,14}$ or lymphoma mimicking HCL. ${ }^{15}$ Because treatment of HCL is very different from that of malignant lymphoma, the correct diagnosis is of the utmost importance.

The patient herein described had both HCL and diffuse histiocytic lymphoma. The case is reported not only because of its rarity, but also to shed some light on the nature of HCL.

\section{Report of case}

In August 1978, a 68-year-old white man was admitted to the Veteran's Administration Hospital in Buffalo, New York, with complaints of fullness in the left upper quadrant of 3 months' duration and a 10-pound weight loss over the previous 5 months. The only other symptom was slight fatigue.

In 1971 , he had been told by his private physician that his spleen was enlarged; he had been followed without further evaluation or therapy until, in 1974, he was told that his spleen was no longer palpable. His past history was remarkable for rheumatic heart disease in 1930 (aged 20 years), a hemorrhoidectomy in 1943, cardiac dysrhythmia in 1955, and in 1974 latent syphilis treated with penicillin and a transurethral prostate resection for benign disease. Blood counts going back to 1955 had been normal. Habits included only mild ethanol ingestion and cigarette use. His family history was unremarkable.

Physical examination in August 1978 was normal except for splenomegaly $8 \mathrm{~cm}$. below the left costal margin. Neither hepatomegaly nor lymphadenopathy was noted. A complete blood count (CBC) showed the following: hemoglobin, $12.4 \mathrm{gm} . / \mathrm{dl}$.; hematocrit, 38.9 percent; and leukocytes, $10,700 / \mathrm{cu}$. mm., with 39 percent polymorphonuclear leukocytes, 57 percent atypical lymphocytes, 1 percent eosinophils, and 3 percent monocytes. The reticulocyte count was 3.3 percent. Hemoglobin electrophoresis yielded normal results, and coagulation studies were normal. RPR was positive, with a negative fluorescent treponemal antibody absorption test. The erythrocyte sedimentation rate was $24 \mathrm{~mm}$./hour. Anti- 
nuclear antibody and Coombs' tests and serum chemistry values were normal. The chest $\mathrm{x}$-ray film was negative. A liver-spleen scan showed splenomegaly, as did an otherwise normal gallium ${ }^{67}$ scan. A liver biopsy disclosed mild, nonspecific, reactive hepatitis. Erythroid and granulocytic hyperplasia were revealed by a bone marrow biopsy. Hairy cell leukemia was considered from the peripheral smear.

The patient was followed without therapy until August 1979, when nausea and vomiting after meals, malaise, and a 7-pound weight loss developed. Physical examination then revealed the spleen to be palpable $18 \mathrm{~cm}$. below the left costal margin. No hepatomegaly or lymphadenopathy was noted. The $\mathrm{CBC}$ demonstrated the following: hemoglobin, $10.0 \mathrm{gm} . / \mathrm{dl}$.; hematocrit, 31.1 percent; leukocytes, $12,800 / \mathrm{cu}$. $\mathrm{mm}$., of which 79 percent were atypical lymphocytes (slightly enlarged with a central nucleus and faint cytoplasmic projections); and platelets, $205,000 / \mathrm{cu}$. $\mathrm{mm}$. Serum chemistry results were normal except for values of serum glutamic-pyruvic transaminase $(75 \mathrm{mU} . / \mathrm{ml}$. [normal, $15-40 \mathrm{mU} . / \mathrm{ml}$.]), lactic dehydrogenase $(940 \mathrm{mU} . / \mathrm{ml}$. [normal, 100-225 mU./ $\mathrm{ml}$.$] ), and alkaline phosphatase (175 \mathrm{mU} . / \mathrm{ml}$. [normal, $30-115 \mathrm{mU} . / \mathrm{ml}$.]). The total bilirubin value was $1.4 \mathrm{mg} . / \mathrm{dl}$. Coagulation studies yielded normal results. A liverspleen scan revealed an enlarged spleen $(12 \times 20 \mathrm{~cm}$.).

For diagnostic purposes, the patient underwent splenectomy, with a 3,800 -gm. spleen and a small accessory spleen being removed. Pathologic examination results were compatible with histiocytic lymphoma. Postoperatively, the CBC showed the following: hemoglobin, $14.0 \mathrm{gm} . / \mathrm{dl}$; hematocrit, 40 percent; leukocytes, $50,600 / \mathrm{cu}$. mm., with 32 percent polymorphonuclear leukocytes, 60 percent atypical lymphocytes, 4 percent band forms, 3 percent monocytes, and 1 percent eosinophils; and platelets, 1,005,000/cu. mm. (Aspirin was prescribed for thrombocytosis.)

In September 1979, bilateral cervical and inguinal lymphadenopathy developed. The $\mathrm{CBC}$ and serum chemistry values were essentially unchanged from those at previous discharge. A left supraclavicular lymph node biopsy revealed diffuse histiocytic lymphoma. Cell surface studies of the biopsied lymph node material revealed a large percentage of cells forming EA and EAC rosettes and high Ia-like antigen, which suggested B-cell proliferation. The chest $\mathrm{x}$-ray revealed a widened mediastinum and prominent left hilum. The gallium ${ }^{67}$ scan showed increased uptake in the mediastinum, left lobe of the liver, and bilateral inguinal region, and questionable uptake in the cervical and abdominal regions. A bone marrow biopsy showed possible hairy cells, and electron microscopy of the peripheral blood revealed cells consistent with HCL. Tartrate resistant acid phosphatase (TRAP) staining of the mononuclear cells was negative.

The patient was treated with cyclophosphamide $(750$ $\mathrm{mg} . / \mathrm{m}^{2}{ }^{2}$ intravenously day 1$)$, doxorubicin $\left(50 \mathrm{mg} . / \mathrm{m} .^{2}\right.$ intravenously day 1$)$, vincristine $\left(1.5 \mathrm{mg} . / \mathrm{m} .^{2}\right.$ intravenously day 1$)$, and prednisone $\left(100 \mathrm{mg} . / \mathrm{m} .^{2}\right.$ orally days 1 through 5) (CHOP). The size of the involved lymph

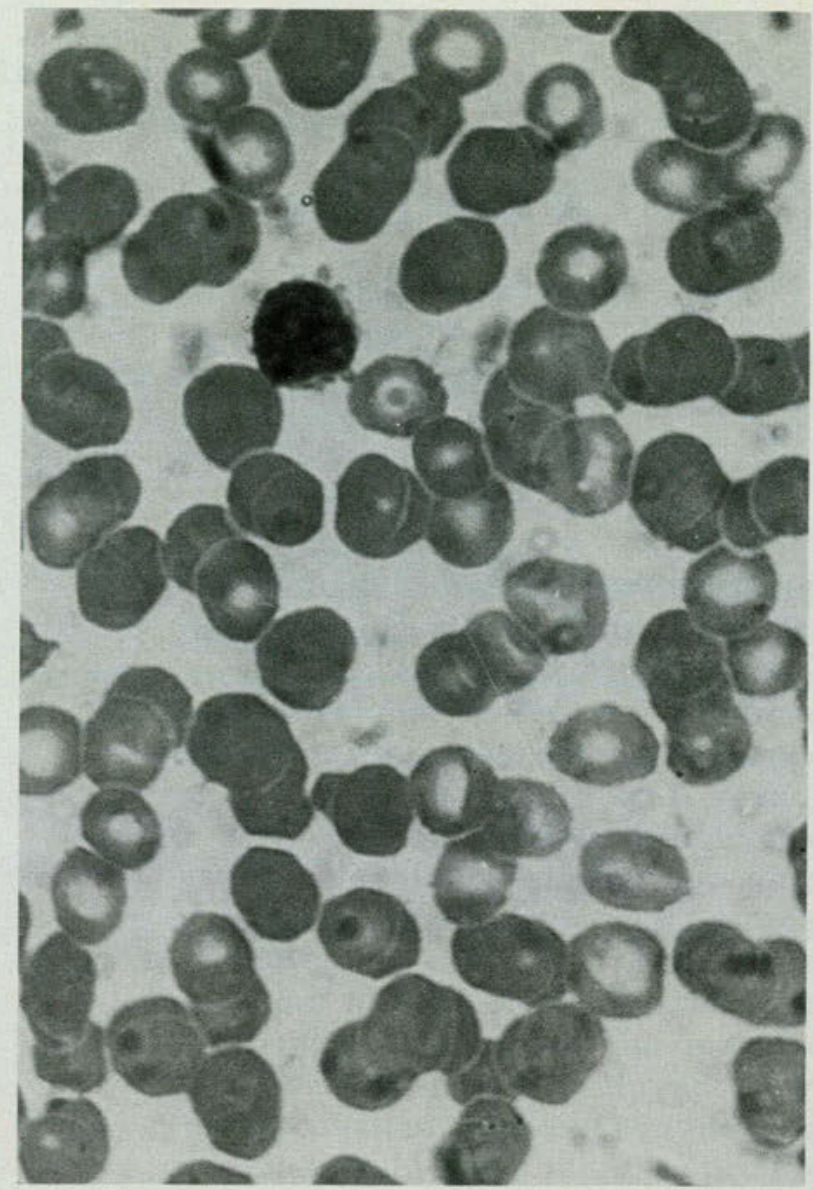

Fig. 1. Original peripheral smear shows mononuclear cells with irregular cytoplasmic projections (Wright-Giemsa stain, original magnification $\times 1,000)$.

nodes promptly decreased, but approximately 3 weeks later, on November 21,1979, the patient was readmitted with complaints of fatigue, low-grade temperature, and anorexia. Physical examination revealed reappearance of generalized lymphadenopathy, including mesenteric nodes and hepatomegaly. He received three further courses of CHOP, with resolution of the lymph node enlargement, but rapid regrowth occurred between courses. Eventually leukopenia developed, then pneumonia, and the patient died January 18, 1980.

Autopsy showed massive involvement of all lymph nodes by histiocytic lymphoma. There was also microscopic involvement by lymphoma of the heart, kidneys, urinary bladder, esophagus, striated muscle, and thymus.

\section{Morphologic and immunologic studies}

Light microscopic examinations. Peripheral smears were subjected to Wright-Giemsa staining in the usual manner and examined by light microscopy under oil immersion. The initial smear from 
August 1978 revealed the presence of abnormal mononuclear cells with irregular cytoplasmic borders. The cells varied in diameter from $10-20 \mu$. The nucleus was predominantly round or oval, but occasionally indented or bilobed. The location of the nucleus was usually eccentric. The nuclear chromatin pattern was loose and lacy in appearance. Occasional nucleoli were seen. The amount of cytoplasm varied, but usually was abundant, more so than in normal lymphocytes. Staining of the cytoplasm showed it to be pale blue. No cytoplasmic granules were seen (Fig. 1).

Bone marrow biopsy in September 1979 showed diffuse, mononuclear cell infiltration with cells suggestive of hairy cells similar to those seen in the peripheral blood.

The excised spleen showed a smooth, slate-colored surface. On section, it contained small (1-2 $\mathrm{mm}$. diameter), whitish-gray nodules diffusely scattered throughout (Fig. 2). Microscopically, the nodules were made up of large, pleomorphic cells with vesicular nuclei and prominent nucleoli. Scattered mitoses were present.

Biopsy of the left supraclavicular lumph node showed a totally effaced architecture. The node was infiltrated diffusely by large and medium-sized pleomorphic cells. Some of them were round or oval. Scattered mitoses were also present (Fig.3).

Electron microscopic study. Examination of peripheral blood under electron microscopy in September 1979 revealed mononuclear cells with ruffled membranes and microvilli on the cell surface (Fig. 4).

Cytochemical study. Histochemical staining of the abnormal mononuclear cells with acid phosphatase was inhibited by the addition of tartaric acid (TRAP negative). This result is unlike that of classic mononuclear cells in HCL stained with acid phosphatase that are not inhibited by (that is, are resistant to) tartaric acid (TRAP positive) as described by Yam and associates. ${ }^{16}$

Immunologic surface markers. Cell surface marker studies of the lymph node excised September 1979 were performed in the usual fashion described by Han and coworkers. ${ }^{17}$ Results are shown in Table 1 . There was a large population of B cells, as noted by the increased percentage of EA and EAC rosettes and the Ia-like antigen. Analysis of surface immunoglobulins revealed $\kappa$ light chain with $\alpha, \gamma$, and $\mu$ heavy chains.

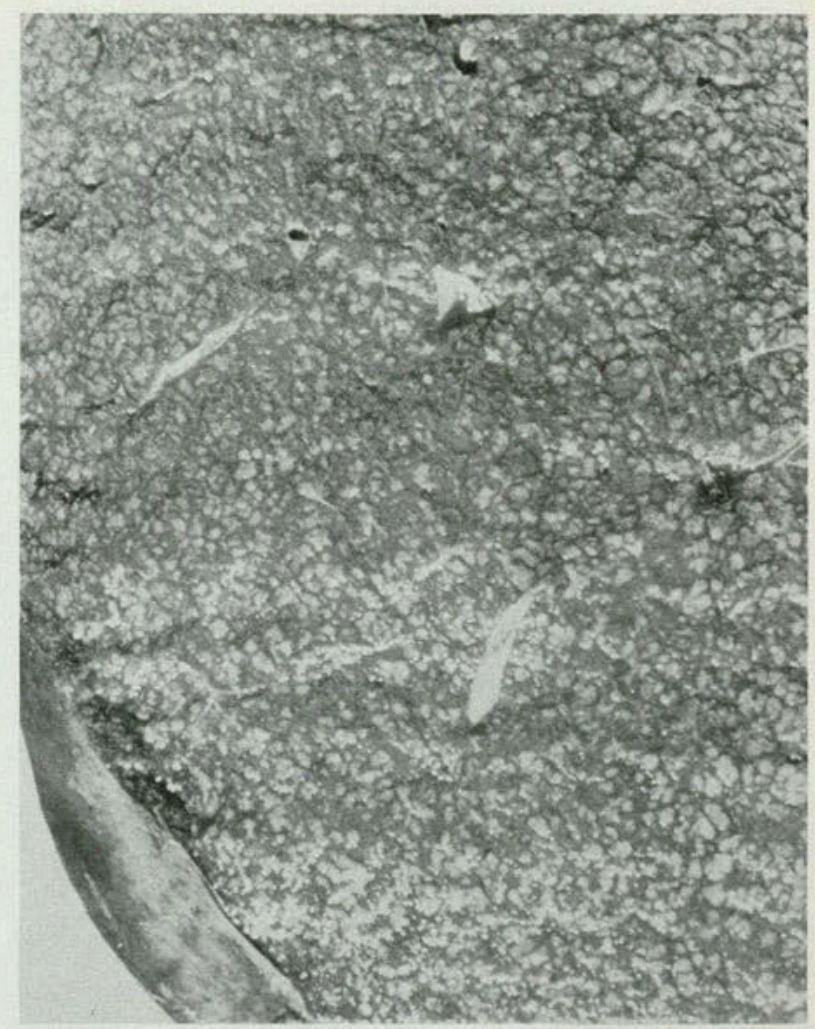

Fig. 2. Close-up view of cut surface of spleen (original magnification $\times 1$ ).

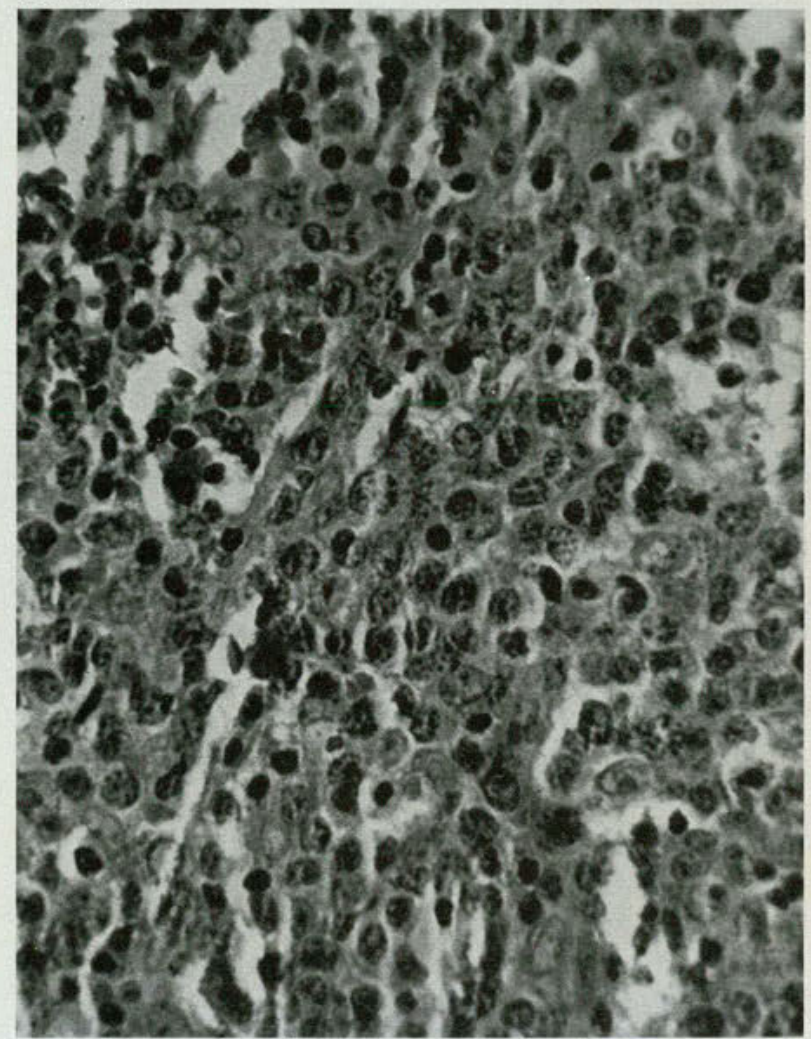

Fig. 3. Lymph node with large pleomorphic cells containing vesicular nuclei and prominent nucleoli (hematoxylin-eosin stain, original magnification $\times 400$ ). 


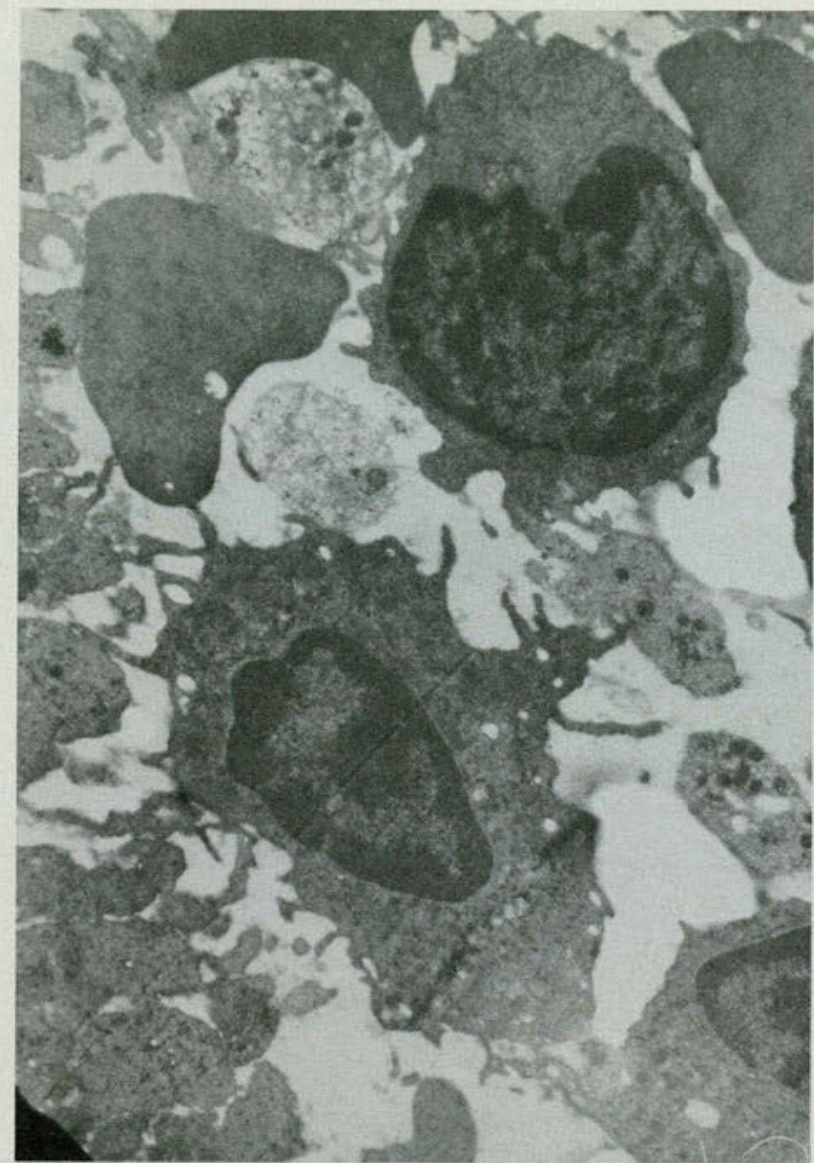

Fig. 4. Electron micrograph of mononuclear cells showing irregularly elongated microvilli or cytoplasmic processes ( uranyl acetate-lead citrate stain, original magnification $\times 3,000$ ).

\section{Discussion}

Three cases of coexistent HCL and histiocytic lymphoma have been reported ${ }^{10-12}$ in detail previously. Only in Franssila's case ${ }^{11}$ did the patient have HCL for an extended period before lymphoma developed. It becomes interesting, therefore, to speculate on the coexistence of these two disorders.

In 1928 , Richter ${ }^{18}$ described a patient with chronic lymphocytic leukemia (CLL) whose condition developed into what was then called reticulum cell sarcoma. Similar patients with smoldering atypical CLL that then transformed into a rapidly progressive disease with generalized lymphadenopathy, hepatosplenomegaly, fever, and weight loss have been described subsequently. In these patients, the lymph node histologic pattern was not that of CLL, but of a more malignant lymphoma, reticulum cell sarcoma, or, according to the Rappaport classification, histiocytic lymphoma.

\begin{tabular}{|lc|}
\hline TABLE 1. CELL SURFACE MARKER STUDIES. \\
\hline Surface and antigen marker & $\begin{array}{l}\text { Percentage } \\
\text { positive }\end{array}$ \\
\hline E rosettes & 6.8 \\
EA rosettes & 65.0 \\
EAC rosettes & 39.6 \\
Ia-like antigen & 93.0 \\
cALL antigen & 0.0 \\
SmIg chains & \\
$\kappa$ & 59.9 \\
$\lambda$ & 0.9 \\
$\alpha$ & 43.0 \\
$\delta$ & 1.8 \\
$\gamma$ & 63.0 \\
$\mu$ & 86.4 \\
\hline
\end{tabular}

Much of the argument for such an association of the two disorders in Richter's syndrome now stems from immunologic studies. It has been suggested that the more mature small lymphocyte of CLL transforms or dedifferentiates into the less mature, larger cell of histiocytic lymphoma. ${ }^{19}$ Common ground between the two disorders may lie in the fact that CLL and the majority of histiocytic lymphomas are of B-cell origin..$^{20,21}$

There have been many studies of the immunologic characteristic of hairy cells. Most reports show that the hairy cell has the same cell surface markers as B lymphocytes. ${ }^{2,6,13,22}$ Cases of coexistent HCL and histiocytic lymphoma may be examples of dedifferentiation of a more mature B lymphocyte into a second B-cell malignancy, as in Richter's syndrome or as Salmon and Seligmann ${ }^{22}$ have suggested.

The association between the two conditions in the present case is not definitive. Cell surface marker studies were not obtained at the diagnosis of HCL, so it can only be surmised that the hairy cells had monoclonal B cell markers. However, this conjecture would concur with the recent literature..$^{13,23}$ It is now generally accepted that the monoclonality represents the proliferative expansion of a neoplastic clone arising from a single cell. It should be pointed out that our patient's lymph node cells had $\kappa$-type monoclonal light chain SmIg. Of interest is the fact that the lymph node cells expressed polyclonal staining patterns of heavy chain $\operatorname{SmIg}(\alpha, \gamma, \mu)$. This polyclonal staining pattern may be caused by the nonspecific adsorption of serum Ig by Fc receptors on these lymph node cells (65 percent EA-positive cells). Polyclonal heavy chain SmIg staining patterns due to nonspecific adsorption of serum Ig by Fc receptors on chronic lymphocytic leukemia cells or HCL cells have been 
reported previously. ${ }^{2,23-25}$ However, this expression of a high percentage of heavy chain $\operatorname{SmIg}(\alpha, \gamma, \mu)$ may be similar to the findings of Jansen and coworkers ${ }^{26}$ who reported the most frequent isotypes in 64 cases of HCL studied: $\gamma, 32$ percent; and $\alpha-\gamma, 25$ percent.

It may also be argued that the patient did not, in fact, have HCL because TRAP activity was not demonstrated. However, negative tartrate resistance exists in approximately 10 percent of patients with HCL. ${ }^{27}$ The electron microscopic features were consistent with those of HCL. ${ }^{28}$

A further possibility is that the development of histiocytic lymphoma was just coincidental in a patient with HCL. However, the fact that both disorders have B-cell markers raises the possibility of a relationship.

\section{Conclusion}

It appears that in our patient, a slowly progressive, presumably B-cell lymphoproliferative disorder, HCL, progressed or transformed into a more highly malignant and aggressive B-cell disorder, histiocytic lymphoma. Whether the two entities have only similar characteristics or are part of a spectrum of a single disorder can only be speculated. Closer observation of patients with HCL should give further insight into these possibilities.

Appreciation is expressed to Dr. Untae Kim and Mr. Soon Won Chai for their technical assistance with the electron micrographs and to Dr. Tin Han for his guidance in preparation of this paper.

1. Golomb, H.M., Catovsky, D., and Golde, D.W.: Hairy cell leukemia. A clinical review based on 71 cases. Ann Intern Med 89:677-83, Nov 78

2. Naeim, F., et al.: "Hairy cell" leukemia. A heterogeneous chronic lymphoproliferative disorder. Am J Med 65:479-87, Sep 78

3. Golomb, H.M.: Hairy cell leukemia. The importance of accurate diagnosis and management. Adv Intern Med 29:245-69, 1984

4. Gransar, A et al: Characterization of blood mononuclear and cultured cells in hairy cell leukemia. Am J Clin Pathol 79:733-7, Jun 83

5. Janckila, A.J., et al.: Phenotype of the hairy cells of leukemic reticuloendotheliosis defined by monoclonal antibodies. Am J Clin Pathol 79:431-7, Apr 83

6. Naeim, F., Bergmann, K., and Gatti, R.A.: Membrane receptors and their redistribution in lymphoproliferative disorders. Blood 54:648-58, Sep 79

7. Gamliel, H., et al.: Hairy cell leukemia. Reevaluation of cell surface features under the scanning electron microscope, using the "GTGO" air drying and critical point drying procedures. Scan Electron Microse ( $\mathrm{Pt}$ 4):1665-78, 1985

8. Hsu, S.M., et al.: Hairy cell leukemia still a B cell neoplasm (letter) Am J Clin Pathol 85:252-4, Feb 86
9. Worman, C.P., et al.: The nature of hairy cells - a study with a panel of monoclonal antibodies. Scand J Haematol 30:223-6, Feb 83

10. Adler, S.S., Shetty, J., and Golomb, H.M.: Coexistence of leukemic reticuloendotheliosis and histiocytic lymphoma. A case report. Cancer 43:1872-80, May 79

11. Franssila, K.O: Coincidental hairy cell leukemia and large cell malignant lymphoma. Arch Pathol Lab Med 103:437-9, Aug 79

12. Vardiman, J.W., Variakojis, D., and Golomb, H.M.: Hairy cell leukemia. An autopsy study. Cancer 43: 1339-49, Apr 79

13. Budman, D.R., et al: Massive lymphadenopathy mimicking lym phoma in leukemia reticuloendotheliosis. Am J Med 66:160-2, Jan 79

14. Jacobs, $P$, Knottenbelt, $E$, and Jacobs, L: Hairy cell leukaemia masquerading as malignant lymphoma. S Afr Med J 62:559-61, Oct 82 15. Neiman, R.S., Sullivan, A.L., and Jaffe, R.: Malignant lymphoma simulating leukemic reticuloendotheliosis. A clinicopathologic study of ten cases. Cancer 43:329-42, Jan 79

16. Yam, L.T., Li, C.Y., and Lam, K.W.: Tartrate-resistant acid phos phatase isoenzyme in the reticulum cells of leukemic reticuloendotheliosis. N Engl J Med 284:357-60, 18 Feb 71

17. Han, T., et al.: T-cell malignant lymphoma. NY State J Med 80:789-94, Apr 80

18. Richter, M.N.: Generalized reticular cell sarcoma of lymph nodes associated with lymphatic leukemia. Am J Pathol 4:285-92, Jul 28

19. Armitage, J.O., Dick, F.R., and Corder, M.P.: Diffuse histiocytic lymphoma complicating chronic lymphocytic leukemia. Cancer 41:422-7, Feb 78

20. Brouet, J.C., et al.: Membrane markers in "histiocytic" lymphomas (reticulum cell sarcoma). J Natl Cancer Inst 56:631-3, Mar 76

21. Lukes, R.J., et al:: A morphologic and immunologic surface marker study of 299 cases of non-Hodgkin lymphomas and related leukemias. Am J Pathol 90:461-86, Feb 78

22. Salmon, S.E., and Seligmann, M.: B-cell neoplasia in man. Lancet $2: 1230-3,23$ Nov 74

23. Parker, J.W.: Immunologic basis for the redefinition of malignant lymphomas. Am J Clin Pathol 72:670-86, Oct (Suppl.) 79

24. Golomb, H.M., et al.: Surface immunoglobulins on hairy cells of 55 patients with hairy cell leukemia. Am J Hematol 12:397-401, 1982

25. Jansen, J., et al.: Cell markers in hairy cell leukemia studied in cells from 51 patients. Blood 59:52-60, Jan 82

26. Jansen, J., et al.: Hairy cell leukemia. Its place among the chronic B cell leukemias. Semin Oncol 11:386-93, Dec 86

27. Burke, J.S., Byrne, G.E., Jr., and Rappaport, H.: Hairy cell leukemia (leukemic reticuloendotheliosis). I. A clinical pathologic study of 21 patients. Cancer 33:1399-1410, May 74

28. Catovsky, D., et al.: Hairy cell leukemia (HCL) variant. An inter mediate disease between HCL and B prolymphocytic leukemia. Semin Oncol 11:362-9, Dec 84

Accepted for publication in September 1986. Updating, as necessary, has been done by the authors.

This research has been supported, in part, by USPHS Grant CA-09108 from the National Cancer Institute.

When this paper was written, Dr. Rothman was a fellow in medical oncology, Roswell Park Memorial Institute, Buffalo, New York. He is a recipient of the American Cancer Society Regular Clinical Fellowship (CF/4603A). He is now an assistant professor of medicine, University of Medicine and Dentistry of New Jersey, School of Osteopathic Medicine, Camden, New Jersey. Dr. Spaulding is chief, Division of Oncology, and Dr. Montes was chief, Department of Pathology, Veteran's Administration Hospital, Buffalo, New York.

Dr. Rothman, University of Medicine and Dentistry of New Jersey, School of Osteopathic Medicine, 401 Haddon Avenue, Camden, New Jersey 08103. 


\section{How to recognize a quack when you see one.}

Quack medical products. They're everything from baldness remedies to cancer cures. All eventually prove to be a waste o money; many actually pose a serious threat to your health.

How do you distinguish a quack medical product from the real thing? For a start- if it sounds too good to be true, it probably is. Quack medical products usually claim simple solutions, miracle cures, or amazing scientific breakthroughs. Many flaur testimonials from satisfied users. To be sure whether a medical product is a quack, check with your doctor or pharmacist first. Because the next dead duck could be you.

For a free brochure, mail to:
Quackery, HFE 55, Rockville, Maryland 20857.
NAME (please print)
ADDRESS

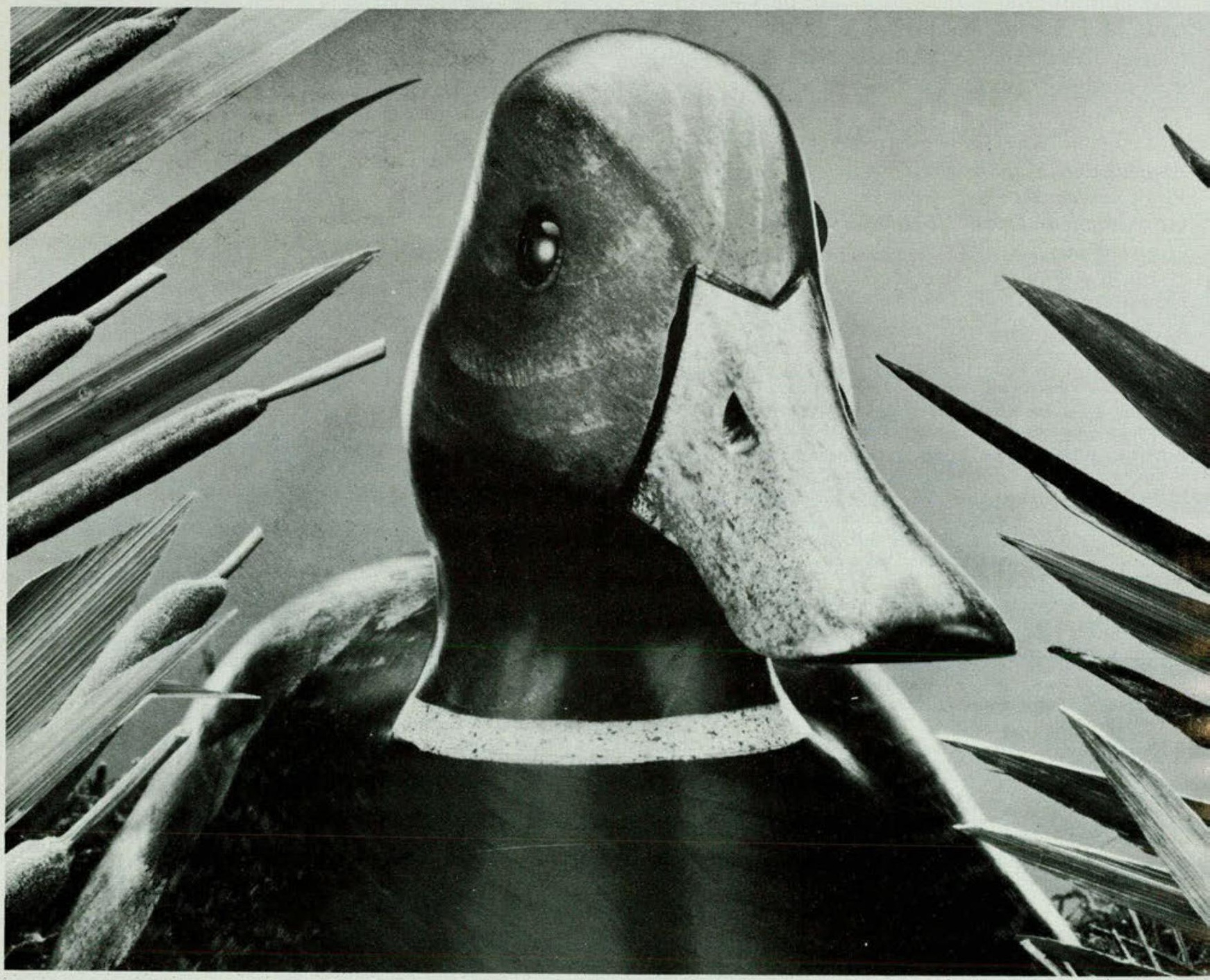

